\title{
Growth-Related and Antennular Amputation-Induced Changes in the Olfactory Centers of Crayfish Brain
}

\author{
Renate Sandeman, Daniel Clarke, David Sandeman, and Mark Manly \\ School of Biological Science, University of New South Wales, Sydney NSW 2052, Australia
}

Freshwater crayfish increase in size throughout their lives, and this growth is accompanied by an increase in the length of the appendages and number of mechanoreceptive and chemoreceptive sensilla on them. We find that in the Australian freshwater crayfish Cherax destructor, neuropil volumes of the olfactory centers increase linearly with body size over the entire size range of animals found in their natural habitat. The number of cell somata of two groups of interneurons associated with the olfactory centers (projection neurons and small local neurons) also increases linearly with the size of the animals. In contrast, axon counts of interneurons that represent a nonolfactory input to the olfactory centers show that these reach a total number in the very early adult stages that then remains constant regardless of the size of the animal. Only the axon diameter of these interneurons increases linearly with body size. Amputation of the antennule and olfactory sensilla reduces the number of projection and local interneurons on the amputated side. No change in the size of the olfactory centers occurs on the unamputated side. Amputation of the olfactory receptor neurons in crayfish therefore leads not only to a degeneration of the receptor cell endings in the olfactory lobe but also to a trans-synaptic response in which the number of higher order neurons decreases. Reconstitution of the antennule and olfactory receptor neurons in small adult crayfish is accompanied by the reestablishment of the normal number of interneurons and neuropil volume in the olfactory centers.

Key words: growth; olfactory centers; crayfish; turnover of olfactory receptor cells; turnover of olfactory interneurons; TUNEL; amputation; trans-synaptic cell death; reconstitution
Crustaceans grow throughout their lives by molting, and the increase in body size is accompanied by the addition of somatic sensory receptors (Letourneau, 1976; Mellon and Alones, 1993; Sandeman and Sandeman, 1996). This ever-increasing neural input requires more synaptic space in the CNS to accommodate it, and in the lobster Homarus americanus, the brain size enlarges in proportion to the size of the body (Helluy et al., 1995). Such an increase in the dimensions of central nervous tissue could be brought about by an increase in the size of the individual elements and their synaptic arborizations or by an increase in the total number of neurons in the brain or both.

Invertebrate nervous systems are often exploited by neurobiologists for the constancy of their neuronal complement and the prospect of being able to uniquely identify individual sensory, central, and motor neurons in the same species and even sometimes between species. This is as true for arthropods, such as the crustaceans that grow in size after reaching their adult form, as it is for those, such as the holometabolous insects, that do not increase their size as adults. The catalog of individually identified interneurons and motorneurons in the crustacean CNS is now fairly substantial, and there appears to be no example of such neurons increasing in number as the animals grow from small to large adults, leading to the notion that much of the arthropod CNS is a predetermined, relatively inflexible and "hard-wired" system. In all cases, the neurons accommodate the increase in body size and number of peripheral receptors with larger synaptic arborizations and longer axons with greater diameters. Although

Received Nov. 3, 1997; revised June 4, 1998; accepted June 8, 1998.

This work was funded by the Australian Research Council.

Correspondence should be addressed to R. E. Sandeman, Biological Sciences, University of New South Wales, Sydney NSW 2052, Australia.

Copyright (C) 1998 Society for Neuroscience $0270-6474 / 98 / 186195-12 \$ 05.00 / 0$ a measure of plasticity is exhibited by these fixed elements, particularly in some motor systems, this is always limited to changes within single neurons (Atwood and Wojtowicz, 1986; Stewart and Atwood, 1992).

In contrast, recent evidence has shown the presence of cell proliferation centers within the adult brains of insects (Bieber and Fuldner, 1979; Technau, 1984; Cayre et al., 1994, 1996) and crustaceans (Harzsch and Dawirs, 1996; Harzsch and Schmidt, 1996; Harzsch et al., 1997; Schmidt, 1997) where neurons are born throughout the lives of the animals. In all cases the proliferation centers are among neurons that are related to the sense of olfaction. In crustaceans, therefore, the increase in synaptic space needed to accommodate additional receptor input may be achieved by the addition of new neurons and not only by the enlargement of the synaptic arbors of existing neurons. The olfactory neuron proliferation is also unique because the new neurons are formed by equal division instead of the more usual unequal division of stem cells (neuroblasts) that produce central neurons in early development.

A common feature of vertebrate and invertebrate systems is the trophic relationship between the olfactory receptor neurons and their target interneurons during development and in adults (Monti-Graziadei and Graziadei, 1979, 1992; Gascuel and Masson, 1990; Sandeman and Sandeman, 1990; Schwob et al., 1992; Brunjes, 1994; Hildebrand et al., 1997). Olfactory systems also exhibit plasticity. For example, closure of the external naris of rats during development leads to an increase in apoptotic cell death in the glomerular and granule cells of the olfactory bulb (Najbauer and Leon, 1995), whereas chronic exposure of rat pups to a mixture of odors results in an increased number of cells in the olfactory bulb (Rosselli-Austin and Williams, 1990). In moths, trans-sexually grafted antennae change the olfactory behavior 
(Schneiderman et al., 1982, 1986; Schneiderman and Hildebrand, 1985), and there are many examples of age- and experiencerelated changes in the olfactory areas of the brains of fruit flies (Heisenberg et al., 1995), honeybees (Winnington et al., 1996), and ants (Gronenberg et al., 1996).

The crayfish olfactory system is a particularly interesting model with regard to both the trophic relationships between the olfactory receptors and their target neurons and neuronal plasticity. The animals live for many years during which time the size of the brain increases (Helluy et al., 1995; Schmidt, 1997). They also possess strong powers of regeneration and can regenerate lost appendages, including the antennule and olfactory organ. We know of two very different classes of neurons that are associated with the olfactory centers, both of which can be assayed for size and population number in growing animals. One class is composed of the projection and local neurons that receive their inputs from the olfactory receptor neurons; the other is a set of interneurons that terminate in the accessory lobes (see below) but carry information derived from tactile and visual sensory systems (D. Sandeman et al., 1995).

The olfactory organ of crustaceans consists of an array of special "aesthetasc" sensilla located along the lateral flagellum of the first antennae (the antennules). These sensilla increase in number during body growth (Mellon et al., 1989), and after the animals reach a certain size they are then continuously lost from the tip of the antennule and replaced by new sensilla at the base of the array. The crayfish therefore "turns over" its olfactory receptor neurons (Sandeman and Sandeman, 1996).

Axons from the olfactory receptor neurons on the antennule project exclusively to olfactory glomeruli in the neuropil of paired olfactory lobes in the crayfish brain. These projections are unilateral, and the olfactory lobes are not connected to one another. Within olfactory glomeruli, the olfactory receptor neurons interact with local interneurons and projection or output neurons. The cell somata of local interneurons and projection neurons that are the subject of this investigation lie outside the neuropils in separate clusters designated cluster 9 (local interneurons) and cluster 10 (the projection neurons) (Sandeman et al., 1992).

Two large spherical neuropils, the accessory lobes, lie adjacent to the olfactory lobes and are a prominent and unique feature of the decapod crustacean olfactory centers (Sandeman et al., 1993). The accessory lobes do not receive any primary afferent terminals but are involved in olfactory processing (R. Sandeman et al., 1995; Cohen et al., 1996; Wachowiak et al., 1996). The nonolfactory input to the accessory lobes on which we focus in this study is carried by interneurons in the deutocerebral commissure (D. Sandeman et al., 1995; R. Sandeman et al., 1995). The cell somata of these interneurons lie in cluster 11 .

At the outset, we needed to determine the relationship between body size, deutocerebral interneuron number, olfactory receptor neuron number, and olfactory center size that occurs during normal growth of crayfish. We find that the olfactory centers enlarge with body size by the addition, through cell proliferation, of projection and local neurons over the life of the animal. On the other hand, the increase in the size of the deutocerebral commissure carrying the nonolfactory information to the accessory lobes is entirely the result of an increase in axon diameter.

The information on normal growth was then used as the control against which we were able to deduce the effect of unilateral removal of the olfactory organ on the olfactory centers on both sides of the brain. Unilateral removal of the olfactory organ results in a volume loss in the olfactory lobe and a decrease in the number of olfactory interneurons on the amputated but not on the control side. Reconstitution of the amputated antennule is attended by the reestablishment of the normal olfactory lobe volume and, through increased cell proliferation, interneuronal number. We therefore propose that the olfactory receptors in the crayfish are coupled in some way to their target interneurons such that the loss of old and the gain of new receptors during turnover (Sandeman and Sandeman, 1996) is accompanied by a similar process of cell death and proliferation of the target interneurons.

\section{MATERIALS AND METHODS}

Husbandry. Australian freshwater crayfish, Cherax destructor, ranging in size from the first postembryonic stage to adults with a carapace length of $6 \mathrm{~cm}$, were used for this study. The adult animals had been reared in open-air ponds in northern Sydney. Postembryonic and first-stage adult animals were obtained from eggs that hatched in the laboratory. The crayfish were housed individually at $20^{\circ} \mathrm{C}$ in the laboratory in $21 \times 13 \times$ $13 \mathrm{~cm}$ aquaria containing artificial pond water $(17.5 \mathrm{ml}$ of $1 \mathrm{M} \mathrm{NaCL}, 1.75$ $\mathrm{ml}$ of $1 \mathrm{M} \mathrm{KCl}, 1.75 \mathrm{ml}$ of $1 \mathrm{M} \mathrm{MgSO}_{4}, 7.0 \mathrm{ml}$ of $1 \mathrm{M} \mathrm{CaCO}_{3}$, and $7 \mathrm{gm}$ of $\mathrm{NaHCO}_{3}$ in $35 \mathrm{l}$ of reverse osmosis water). They were subjected to a $15 \mathrm{hr}$ light $/ 9 \mathrm{hr}$ dark and fed chicken pellets three times a week.

Embryonic and postembryonic stages. The embryonic development of Cherax has been described according to a staging system in which egg laying is $0 \%$ and hatching from the egg is $100 \%$ (Sandeman and Sandeman, 1991). We use this system here. The eggs hatch in approximately $40 \mathrm{~d}$ at $20^{\circ} \mathrm{C}$ to produce an individual that is attached to the swimmerets of the mother by a filament extending from the telson. This is postembryonic stage I (POI). The POI has no externalized aesthetascs on the antennules, although the developing sensilla with their olfactory receptor neurons are visible beneath the transparent cuticle of the antennule. The POI molts into postembryonic stage II (POII), in which five aesthetascs are visible. POII animals remain on the swimmerets of the mother until the next molt. The POII molts into the first adult stage (ADI), which is a free-living, feeding individual that leaves the protection of the mother after several days. Although sexually immature, the ADI animals appear to have nervous systems that, apart from their size, are anatomically indistinguishable from adults.

Index of animal size. The body weight of 20 animals was determined to see whether carapace length was a reliable parameter for describing animal size. Individuals were blotted dry and then weighed on a laboratory scale. Regression analyses indicate a good correlation between a crayfish body weight and carapace length $\left(r^{2}=0.9258 ; p<0.0001\right)$. We therefore use the length of the carapace in this study as the index of animal size.

Aesthetasc counts. Counts were made of the aesthetascs on amputated antennules using a light microscope.

Olfactory neuropil volume and interneuron number. Forty-two adult animals, reared in ponds, and 17 juveniles that were raised in the laboratory, were used to establish the relationship between the volume of the olfactory and accessory lobes and animal size (carapace length).

All brains used for volume measurements were exposed by dissection in crayfish saline and then fixed in situ in alcoholic Bouin's. They were then removed, washed, dehydrated, embedded in wax, serially sectioned $(10 \mu \mathrm{m})$, mounted on microscope slides, and processed according to the reduced silver method of Blest and Davie (1980).

Volumes of the neuropils and cell soma clusters were measured from serial sections using a Leica Quantimet 500 image processing and analysis system. The resolution of the camera lucida-based image analysis system is determined by the objective used and ranged between 0.746 $\mu \mathrm{m} /$ pixel $(10 \times$ objective), for the smallest brains, and $2.86 \mu \mathrm{m} / \mathrm{pixel}$ $(2.5 \times$ objective $)$ for the largest brains. Outlines of olfactory neuropils in each section were traced to provide areas. Multiplying the sum of these areas by the section thickness $(10 \mu \mathrm{m})$ provided the volume of each section and the sum of all sections, the volume of the lobe. The olfactory neuropils on both sides of the brain were measured in all experiments, and the mean for a single lobe for each brain was calculated from their sum. Only the synaptic area of the neuropil (i.e., not the axonal tracts) was included in the volume measurements.

Measurements of the volume occupied by the cell somata of the projection neurons and local interneurons were obtained by tracing around the boundaries of the cell clusters, excluding the large tracts of primary neurites that connect the cell somata to the neuropils. To calculate the number of cell somata from the volume of the cell cluster, 
we measured the distance between the centers of neighboring cells at different levels through the cluster. This gives an effective cell diameter that includes the intercellular space between the cells and is slightly larger than the measured diameter of the cells. A mean diameter was obtained from at least 150 cells per animal. An effective cell volume was calculated, and the cell cluster volume was divided by this to provide an estimate of cell number. This method avoids an overestimation of the number of cells in a cluster in which the cells may be small but more loosely packed.

Amputation. The term "amputation" and "reconstitution" will be used throughout this paper in accordance with Monti-Graziadei and Graziadei (1979). Amputation means the complete removal of an appendage. Reconstitution means the complete regrowth of the appendage including aesthetascs, olfactory receptor neurons, mechanoreceptors, blood vessels, etc. Regeneration is used to indicate the regrowth of an axon after axotomy.

Amputations were performed with small scissors, and both flagella of the left antennule of the experimental animals were removed. Adult animals were then individually housed and maintained. Adult brains were fixed in Bouin's and stained with silver as described above. Amputation of antennules of POI animals was conducted while they were still attached to the swimmerets of the mother. After the operation, the animals remained with the mother until the ADI stage. Brains of these juveniles were fixed in $4 \%$ paraformaldehyde in $0.1 \mathrm{M}$ phosphate buffer, $\mathrm{pH} 7.4$, dehydrated, wax-embedded, serially sectioned at $10 \mu \mathrm{m}$, and stained with toluidine blue (Altman, 1980).

Cell proliferation labeling. Bromodeoxyuridine (BrdU, Sigma, St. Louis, MO) was prepared as a $0.5 \%$ solution in crayfish saline and introduced into the animals either by keeping them alive in the solution for $4 \mathrm{~d}$ (POII animals) or injecting the solution into the pericardium (animals with a carapace length $>1.9 \mathrm{~cm}$ ): $0.3 \mathrm{ml}$ of the solution was injected into animals with a carapace length between 1.9 and $3.0 \mathrm{~cm}$, and $0.6 \mathrm{ml}$ of the solution was injected into those with a carapace length of between 3.0 and $4.5 \mathrm{~cm}$. The injected animals were killed after $2.5-3 \mathrm{~d}$. The brains of all treated animals were fixed in $4 \%$ paraformaldehyde in $0.1 \mathrm{~m}$ phosphate buffer, $\mathrm{pH} 7.4$, for $2 \mathrm{hr}$ on a shaker at room temperature before washing, dehydration, clearing, wax embedding, and serial sectioning at $10 \mu \mathrm{m}$. After rehydration, sections were incubated in a $2 \mathrm{~N} \mathrm{HCl}$ solution made up in $0.1 \mathrm{M}$ phosphate buffer and $0.3 \%$ Triton X-100 (PBT) at $37^{\circ} \mathrm{C}$ for $1 \mathrm{hr}$, followed by thorough washing with PBT. An anti-BrdU primary antibody (Amersham, Arlington Heights, IL) and a secondary antibody conjugated with HRP (Amersham) were applied according to the instructions delivered with the kit, and the label was visualized with DAB and $\mathrm{H}_{2} \mathrm{O}_{2}$. Counts of the cells labeled with $\mathrm{BrdU}$ were made from the serial sections of the brains with a microscope equipped with a camera lucida.

TUNEL labeling. Terminal deoxynucleotidyl transferase-mediated biotinylated UTP nick end labeling (TUNEL) has been used as an indication of neuronal cell death (Gavrieli et al., 1992; Negoescu et al., 1996; Thomaidou et al., 1997). We used an in situ FITC cell-death kit (Boehringer Mannheim, Indianapolis, IN) based on a method described by Gavrieli et al. (1992) and the procedure of Nonclerq et al. (1997). Brains were fixed in freshly made $4 \%$ paraformaldehyde, $0.1 \mathrm{M}$ phosphate buffer, $\mathrm{pH} 7.4$, at room temperature for $4 \mathrm{hr}$, dehydrated, wax-embedded, and sectioned at $10 \mu \mathrm{m}$. Sections were dewaxed and rehydrated. To unmask DNA free ends in apoptotic nuclei, sections were covered with distilled water and kept at $60^{\circ} \mathrm{C}$ for $1 \mathrm{hr}$. They were then immersed in ice-cold phosphate buffer for $5 \mathrm{~min}$, incubated in the TUNEL mixture at $37^{\circ} \mathrm{C}$ for $2 \mathrm{hr}$, washed in phosphate buffer, dehydrated, coverslipped, and viewed under FITC fluorescence on an Olympus Vanox photomicroscope. Sections treated with the TUNEL mixture from which the terminal transferase was omitted were used as controls.

The TUNEL method labels DNA fragmentation, which does not always signify apoptosis (Negoescu et al., 1996), and we did not examine the ultrastructure of the TUNEL-labeled cells for specific apoptotic features. Nevertheless we avoided the use of microwave or proteolytic enzyme pretreatment and standardized our fixation and labeling procedures to minimize false-positive labeling. We counted only intensely fluorescing TUNEL profiles, which may represent cells in early apoptotic stages (Negoescu et al., 1996). These occur singly as well as in clusters of two or three (see Fig. 10). No TUNEL profiles were present in the control preparations.

Fixation and counting of deutocerebral commissure interneurons. Brains were fixed in freshly made $4 \%$ paraformaldehyde in $0.1 \mathrm{M}$ phosphate buffer, $2 \%$ glutaraldehyde, and $0.15 \mathrm{~m}$ sucrose at $\mathrm{pH}$ 7.4. They were then post-fixed in osmium tetroxide, dehydrated, and embedded in LR white, medium grade epoxy resin (Bio-Rad, Hercules, CA). No axons leave or join the deutocerebral commissure where it crosses the median sagittal plane of the brain, unambiguously identifiable by the presence of the median cerebral artery. Counts made from sections taken through this plane will contain the same population of interneurons in all animals. The brains were sectioned at $1 \mu \mathrm{m}$ in the sagittal plane, and the sections were stained with toluidine blue. Once the deutocerebral tract and the midline of the brain had been located in $1 \mu \mathrm{m}$ sections, the blocks were trimmed, and thin sections $(120 \mathrm{~nm})$ were cut with a diamond knife and collected on uncoated 200 hex-mesh thin bar grids. The thin sections were stained on the grids with $2 \%$ uranyl acetate and Reynold's lead citrate and washed in $0.02 \mathrm{~N} \mathrm{NaOH}$ followed by distilled water. The grids were given a light coating of carbon in a vacuum evaporator to help stabilize the sections in the electron beam. Axon counts were made by fixing a clear acetate sheet to the micrograph, marking each axon profile, and simultaneously registering it on an incremental counter.

\section{RESULTS}

\section{Growth-related changes}

\section{Olfactory neuropil volume}

Embryonic and POI animals have no outside aesthetascs, but five receptor cell soma clusters are visible within their antennules and there is a small olfactory lobe present in their brains that is approximately three times as large as the accessory lobe (Fig. $1 A)$. The size of the olfactory lobe increases steadily as does the number of aesthetascs (POII, 5; ADI, 8; ADII, 10-12; ADIII, 16-18). Both lobes continue to grow quite rapidly, but it is late in the POII that accessory lobe growth accelerates so that it has a size approximately equal to, and then larger than, the olfactory lobe (Fig. 1B).

Accelerated growth of the accessory lobe continues during ADI, a time when the animal leaves the mother and searches for food. At ADII, the accessory lobe is approximately 3.5 times larger than the olfactory lobe (Fig. 1C). From this point on the accessory lobe/olfactory lobe ratio of 3.5 is maintained for the rest of the animal's life (Fig. $1 E$ ). The development of the olfactory and accessory lobes therefore follows a different path from that known for the lobster Homarus americanus (Helluy et al., 1995).

The olfactory and accessory lobe volumes of animals with a carapace length of 1-6 cm increase linearly with the size of the animals (Fig. 1D). There were no differences between males and females.

\section{Aesthetasc sensilla}

Although we have shown that aesthetascs are lost from the tip of the antennule in adult crayfish, shedding of the aesthetascs does not begin until the animals reach a carapace length of $\sim 1 \mathrm{~cm}$ (Sandeman and Sandeman, 1996). Until this time the increase in the number of sensilla matches the size of the animal. The net gain in sensilla must persist past the stage when shedding begins, because the numerical increase in sensilla matches body size over the entire range of body sizes up to animals with a carapace of 6.5 $\mathrm{cm}$, which were among the largest we have found (Fig. 2).

\section{Olfactory interneuronal cell soma number}

The mean diameters of cell somata of the projection neurons and local interneurons increase during the embryonic to juvenile ADV (carapace length, $\sim 1 \mathrm{~cm}$ ) period, after which they stabilize at $\sim 7.5-8 \mu \mathrm{m}$ and remain this size for the rest of the animal's life (Fig. 3A). 

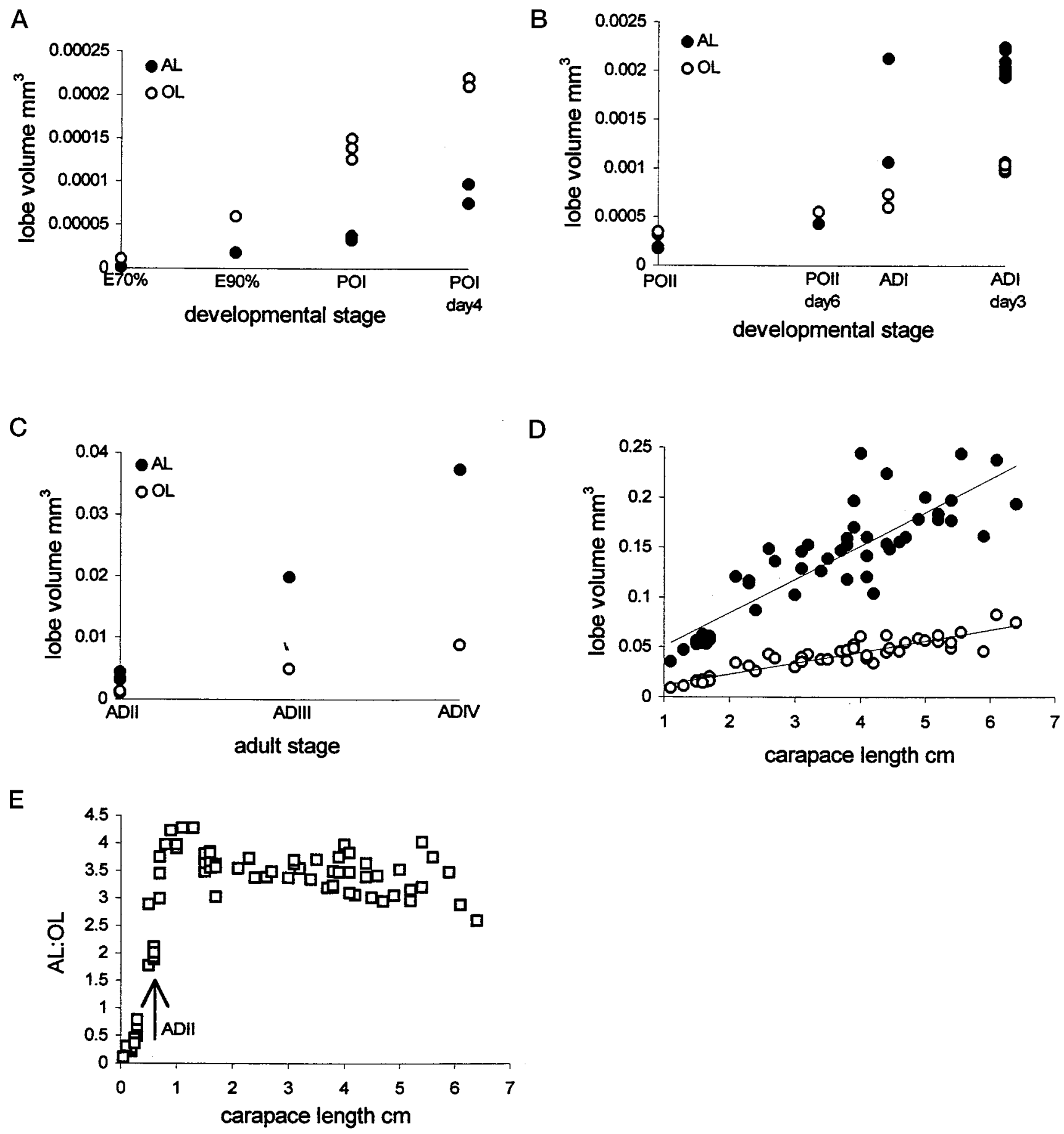

Figure 1. Volume of the accessory and olfactory lobes compared with increasing body size (carapace length). Each point represents the mean of the volume of the left and right accessory lobes $(\bullet)$ and olfactory lobes $(\bigcirc)$ from one individual. $A$, Individuals ranging from $70 \%$ embryos to the POI day 4. The accessory lobes are smaller than the olfactory lobes. $B$, Individuals ranging from POII to ADI day 3 . The accessory lobe is equal in size to the olfactory lobe at the POII and becomes larger than the olfactory lobe during the late POII and the molt to ADI. $C$, ADII-ADIV: at ADII the accessory lobe volume is approximately 3.5 times larger than the olfactory lobe and from this point on the ratio of 3.5:1 is maintained throughout life. $D$, Individuals with carapace length from 1 to $6 \mathrm{~cm}$. The line drawn through the points represents the calculated linear regression $\left(\right.$ accessory lobe, $r^{2}=0.7332, p<$ 0.0001; olfactory lobe, $\left.r^{2}=0.9238, p<0.0001\right)$. E, Combined data over the entire range of animal sizes showing the rapid change in the ratio between the accessory $(A L)$ and olfactory $(O L)$ lobes in the early stages of development and the maintenance of a relatively constant size ratio after ADII (arrow).

The volume occupied by the cell somata of the projection neurons and local interneurons also increases throughout the life of the animal from ADIV to adults with a carapace length of 6.4 cm (Fig. 3B). Cell cluster volume can be taken to reflect cell number because the mean center-to-center distances in animals from ADIV stage and older stabilize at $\sim 9 \mu \mathrm{m}$. The increase in interneuronal cell number in these clusters, therefore, also keeps pace with carapace length (Fig. 3C). 


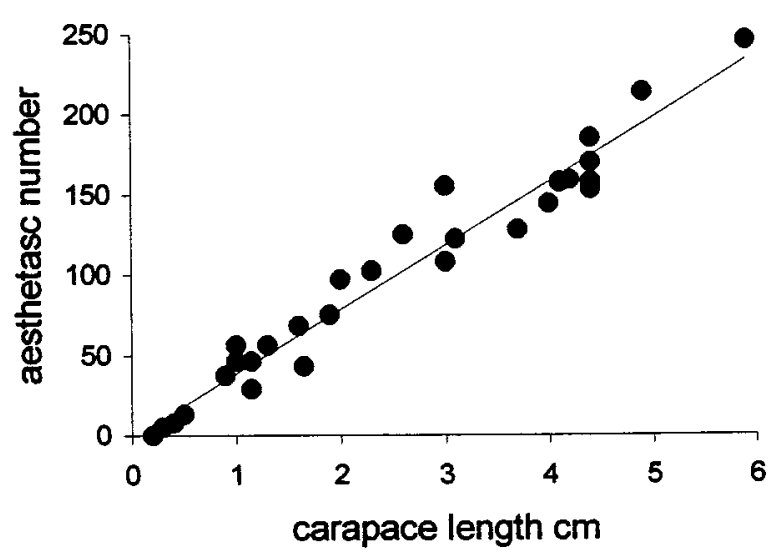

Figure 2. The relationship of the number of aesthetasc sensilla on the antennule to body size ranging from the first appearance of the sensilla at POII (3 mm carapace length) to adults with a carapace length of $6 \mathrm{~cm}$. Despite the shedding that occurs in animals after they have reached a carapace length of $1 \mathrm{~cm}$, there is a linear increase in the number of sensilla with the increase in body size.

\section{Deutocerebral commissure axon counts and diameters}

Two bundles of axons of the deutocerebral commissure can be seen in a toluidine blue-stained cross section taken in the median sagittal plane of the brain of an adult crayfish with a carapace length of $4 \mathrm{~cm}$ (Fig. 4). The axon counts of the postembryonic and immature adult animals (ADII) were taken from electron micrographs because they are too small to be clearly resolved in light micrographs (Fig. 5).

The deutocerebral commissures of eight POI animals contained a mean of 296 axons $(\mathrm{SD}=15.2)$. All of these were about the same size, having a mean diameter of $1.17 \mu \mathrm{m}$ (Fig. 6). All of the axons of the deutocerebral commissure of the POII animals, although slightly larger than those in POI, are also the same size, with a mean diameter of $1.35 \mu \mathrm{m}$ (Fig. 6). The POII animals were sampled throughout this stage, which lasts $6 \mathrm{~d}$, and axon counts in those animals that were nearing the end of the stage were found to be slightly higher than for those at the beginning of the stage. In 6-d-old POII animals (i.e., shortly before molting to ADI), a few very small-diameter fibers appeared along the ventral rim of the tract in an area occupied by the smaller fiber bundle in mature adult commissures (Fig. 5). The commissures of eight POII animals contained a mean of 463 axons $(\mathrm{SD}=26.9)$.

The commissures of eight ADI animals contained a mean of 578 axons $(\mathrm{SD}=6.5)$, with an average axon diameter of $1.4 \mu \mathrm{m}$. The small number of very fine fibers seen at the conclusion of the POII stage were also present in the same ventral position in the commissure in ADI animals (Fig. $5 C$ ), but the axons of the commissure were not separated into fiber bundles with different axon diameters.

The commissures of the eight ADII animals we examined were clearly separated into two bundles with large and small axons (Fig. 5D). We recorded a mean of 411 large fibers $(\mathrm{SD}=14.7)$, with a mean diameter of $2.17 \mu \mathrm{m}$, and a mean of $477(\mathrm{SD}=8.9)$ small fibers, with a mean diameter of $<1 \mu \mathrm{m}$ (Fig. 6)

Good tissue fixation and the relatively large size of the axons in mature adults allowed accurate counts to be made from highpower light micrographs. Both large and small fibers were counted in five animals with carapace lengths ranging from 30 to $60 \mathrm{~mm}$. Despite the different sizes of the animals, axon counts all fell within the same mean of 400 large axons $(\mathrm{SD}=8.5)$ and 1053 small axons $(\mathrm{SD}=38.5)$ (Fig. 7).
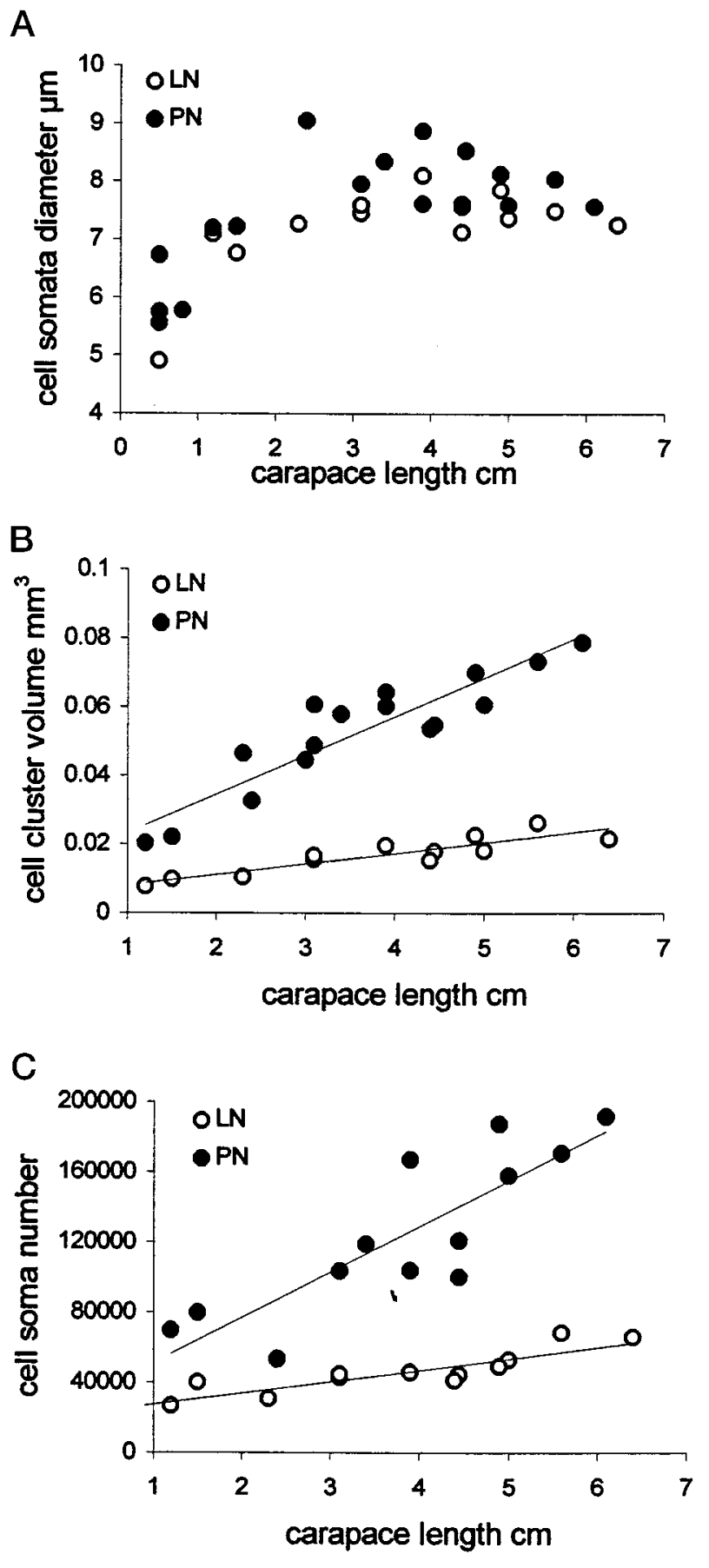

Figure 3. Changes in the size and number of cell somata of local interneurons $(\bigcirc)$ and projection neurons $(\bullet)$ in clusters 9 and $10 . A$, The mean diameter of these cells increases rapidly from POI to the ADIV stage when animals reach a carapace length of $1 \mathrm{~cm}$. Cell soma diameter remains stable at $\sim 8 \mu \mathrm{m}$ for the rest of the animal's life. $B$, The volume of both cell soma clusters increases linearly with body size over the life of the animal. $C$, Cell number, calculated by dividing cell volume (including the intercellular space) into the cluster volume, shows the linear increase in cell number from juvenile to the largest adult, which has $\sim 200,000$ projection neurons and $\sim 5000$ local interneurons.

The axon diameters, however, were not the same in the different sized adults. Large axons ranged from $10 \mu \mathrm{m}$ in an animal with a $3-\mathrm{cm}$-long carapace to $16 \mu \mathrm{m}$ in an animal with a $6-\mathrm{cm}-$ long carapace. Small axons had a diameter of $3 \mu \mathrm{m}$ in the small animal and $4.8 \mu \mathrm{m}$ in the large animal (Fig. 6). 


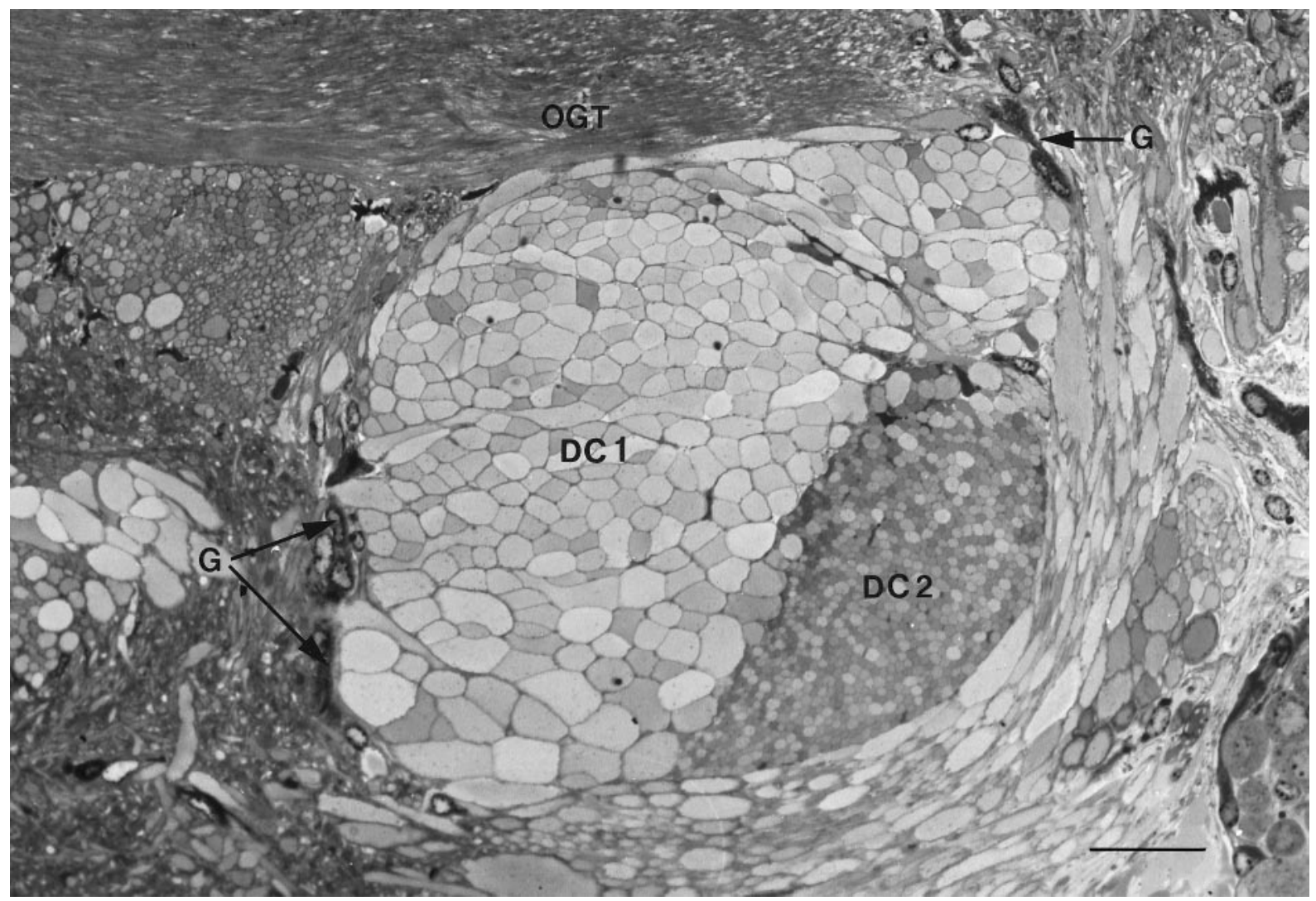

Figure 4. Light micrograph of a median sagittal section through the deutocerebral commissure of an adult animal. Dorsal is at the top of the figure; anterior is to the left. The commissure contains two separate bundles of axons with different diameters (DC 1 and $D C 2)$, separated from neighboring neuropil by glial cells $(G)$ and bounded on the dorsal side by the finer fibers of the olfactory globular tract $(O G T)$. Scale bar, $25 \mu \mathrm{m}$.

\section{Antennular amputation-induced changes}

The interpretation of the changes after amputation relies heavily on the measurements of the normal growth of the olfactory centers in animals that had been reared in conditions of natural light and temperature in outside ponds. Without this information we would not have been able to determine whether the effects of unilateral amputation were confined to the amputated side, nor would we have been able to predict what the normal size of the olfactory centers on the control side should be for an animal of a particular size. We therefore initially compared the control side of the brain of all amputees with the normal growth line. In all cases it was found that the unamputated sides showed no significant change in volume compared with undamaged animals, so that unilateral amputation of antennules does not affect the contralateral olfactory and accessory lobe volume or projection neuron and local interneuron cell number.

The lateral and medial flagella of five animals with carapace lengths between 3.2 and $4 \mathrm{~cm}$ were amputated, and the animals were kept in aquaria for 5 months, after which they were all killed and measurements of the brains were taken. During this time three animals were observed to molt ( 3 months after antennule amputation). Reconstituted stumps of the antennules were amputated again in these animals to prevent any afferents from reaching the olfactory lobes. Measurements of olfactory lobe, accessory lobe, and cell soma cluster volumes were made as before. We found that olfactory and accessory lobe volumes on the amputated side were always reduced when compared with the unamputated side in the same animal. The largest reduction occurred in the olfactory lobes, where the lobes on the amputated side of the brain were reduced by $65-70 \%$ to end up being approximately one-third the size of the lobes on the unamputated side in all animals. Accessory lobes were affected much less than olfactory lobes, being reduced by $\sim 10 \%$ on the amputated side, and in two cases they were not reduced by an amount that exceeded differences that are normally found between the left and right sides of the brain in unamputated control animals. Despite the apparent trend in the reduction of the accessory lobe on the amputated side, subjecting the data to a Mann-Whitney $U$ test revealed the differences to be nonsignificant (two-tailed probability, 0.1032).

Local interneuron cell cluster volume was reduced by $\sim 30 \%$ on the amputated side, and projection neuron cell cluster volume was reduced by $\sim 20 \%$ on the amputated side (Fig. 8). Center-tocenter distances between the cell somata of the local interneurons and projection neurons were no different on the amputated or control sides, nor were cell soma diameters altered.

\section{Cell proliferation}

BrdU-labeled profiles appear in both clusters 9 (local neurons) and 10 (projection neurons) in whole mounts and sections of the brains of small juvenile animals and in vibratome sections and sections of wax-embedded brains of larger animals (carapace length, 1.9-5.0 cm) (Fig. 9). This result confirms that of Harzsch and Schmidt (1996) on Cherax projection neurons and extends their findings in that we also find proliferation among the local interneurons, although far fewer than among the projection neurons.

The labeled neurons in both clusters occur close together in 


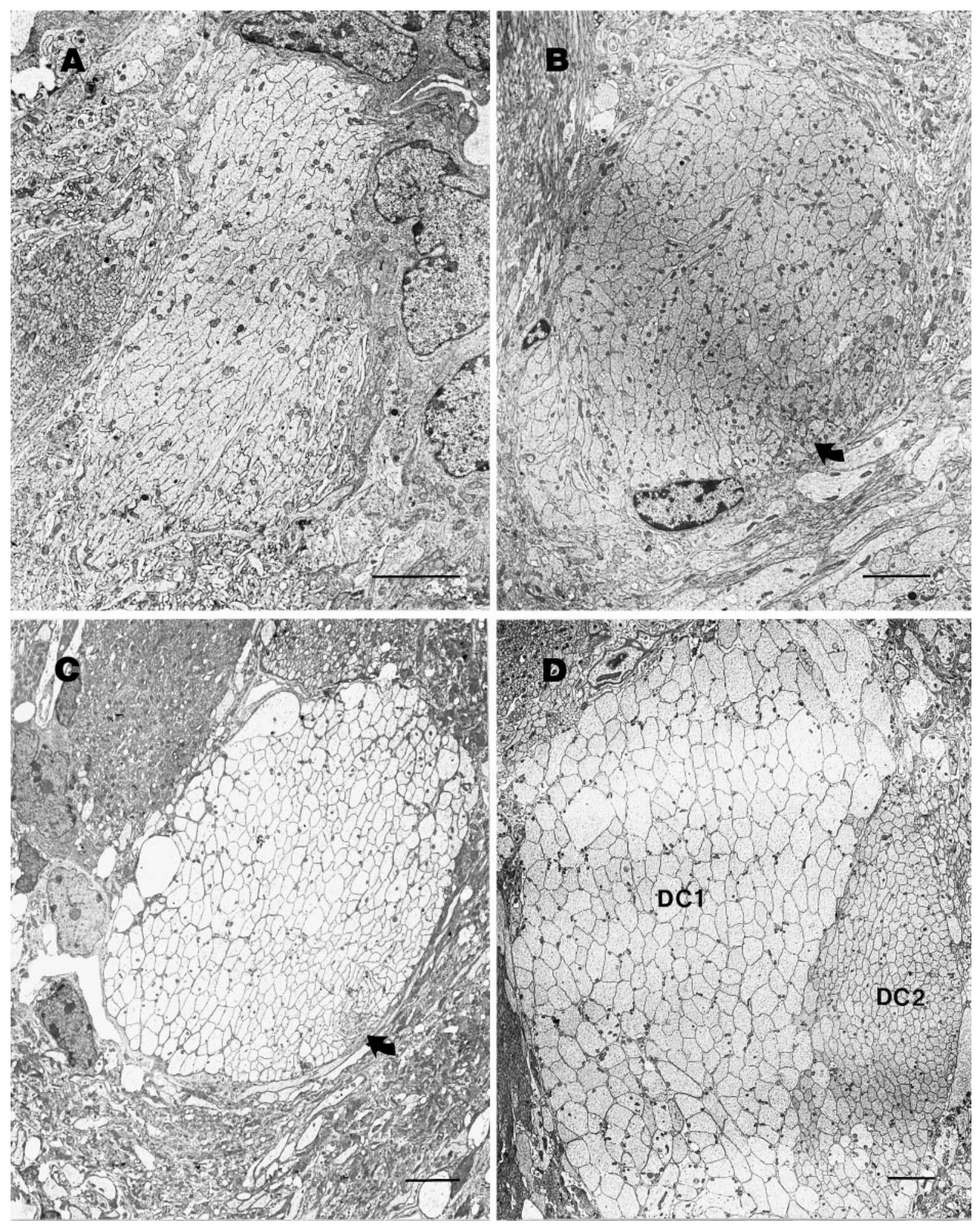

Figure 5. Electron micrographs of median sagittal sections through the deutocerebral commissures of crayfish at stages POI $(A)$, POII $(B)$, ADI $(C)$, and ADII $(D)$. The sections are all oriented with dorsal at the top of the figures; anterior is to the left. $A$, Axons in the commissures of POI animals do not fall into two classes. $B, C$, In POII, some smaller profiles can be recognized along the posterior ventral edge of the commissure (arrow) that appear as a very small bundle in ADI (arrow, $C)$. $D$, Two axon bundles ( $D C 1$ and $D C 2)$, like those in commissures of large adults, appear in ADII. Scale bars, 5 $\mu \mathrm{m}$.

pulse-labeled preparations but spread out toward the periphery of the cell clusters if the animals are left in the BrdU for a long time before fixation. In these animals, both strong and less intensely labeled neurons that had undergone division and still carried the
BrdU trace were found. Dividing the total count of the neurons by the length of the exposure to BrdU provided an estimate of the daily production of new neurons. Our results show a clear correlation between the number of proliferating projection neurons 


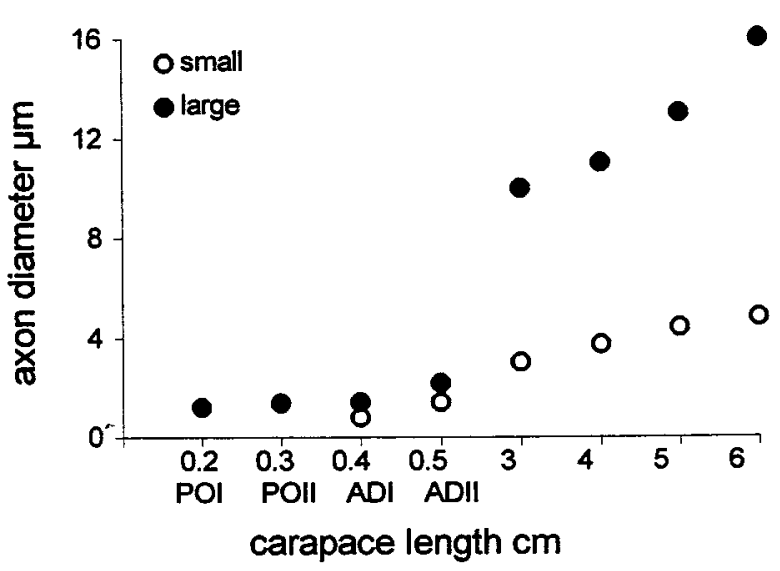

Figure 6. The change in axon diameter with growth. Axons in POI and POII are treated here as large axons. Both small and large axons increase in diameter throughout the growth of the animal over the range of carapace length from 3 to $6 \mathrm{~cm}$ and in proportion to the change in the body size. A calculated regression line (not shown) indicates that this extends back to the smallest adult stages (large axons, $r^{2}=0.9917, p<$ 0.0001; small axons, $\left.r^{2}=0.9802, p=0.0001\right)$.

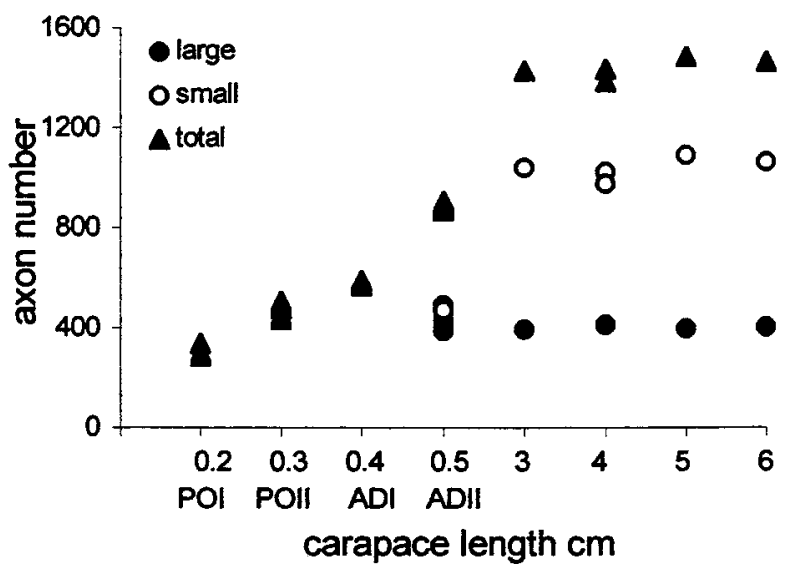

Figure 7. Axon number in the deutocerebral commissure of postembryonic, immature, and mature adults. Each point is the mean of all counts. $\boldsymbol{0}$, Large axons; $\bigcirc$, small axons; $\mathbf{\Delta}$, totals of large and small axons. Total axon counts are shown for POI, POII, and ADI because the axons within the commissures during these stages are all nearly the same size. Total axon number increases through stages POI to ADII and stabilizes by the time the animals have a carapace length of $\sim 3.0 \mathrm{~cm}$ (ADIII). From this time on (ADIV, ADV, and ADVI) there is no increase in the number of large or small axons. The large-diameter axon number stabilizes by stage ADII, so that the increase in the overall total is caused by the addition of small-diameter axons to the commissure.

and the size of the animal: ADI, 300/d; $1.9 \mathrm{~cm}$ carapace length, $60 / \mathrm{d} ; 4.0 \mathrm{~cm}, 44 / \mathrm{d} ; 4.4 \mathrm{~cm}, 45 / \mathrm{d} ; 5.0 \mathrm{~cm}, 40 / \mathrm{d}$. These results fit well with estimates of the numbers of cells that were produced in growing animals, where the size increase and the time taken to achieve it was known. The situation is complicated, however, because the size of an individual crayfish is not necessarily related to its temporal age (see Discussion).

Several large individuals that had undergone unilateral antennular amputation were treated with the BrdU method. One of these survived three molts over a period of 13 months, by which time the reconstituted antennule was approximately two-thirds the size of the control antennule. Counts of BrdU-labeled projection neurons on the reconstituting side of the brain were $\sim 30 \%$ higher than on the control side.

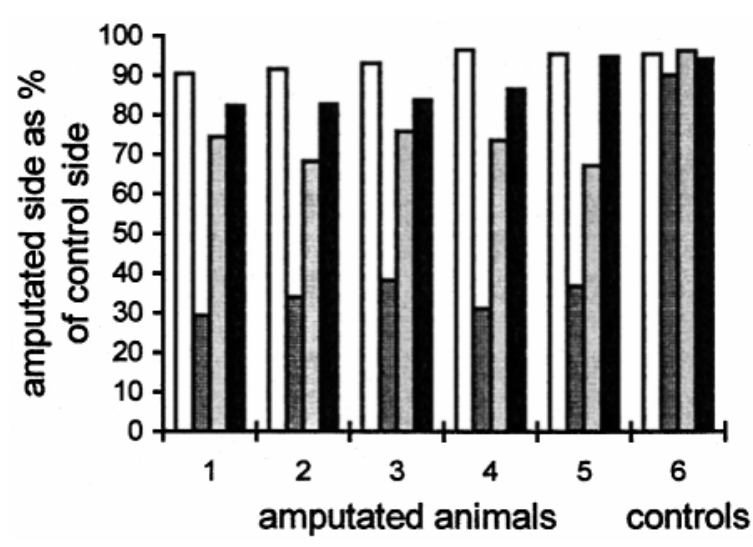

Figure 8. Reduction in olfactory and accessory lobe volume and local interneuron and projection neuron cell number in five adult animals (histograms 1-5) caused by amputation of one antennule. The time between amputation and killing of animals for brain measurement was the same for all five animals. Reconstituted stumps were removed after each molt. Histogram 6 shows the means of normal left/right variation in 38 unamputated control animals. (White columns = accessory lobe volume; light gray = olfactory lobe volume; dark gray = small local neurons; black $=$ projection neurons). Olfactory lobe volume on the amputated side is reduced by $\sim 70 \%$ of the control side in all animals; accessory lobes are reduced by only $\sim 10 \%$ and lie within the normal variation in size between the lobes in an unamputated control animal. Local interneurons on the amputated side are reduced by $\sim 30 \%$, and the projection neurons on the amputated side are reduced by $\sim 20 \%$.

\section{Cell death}

The decrease in the volume of cell clusters 9 and 10 after antennular amputations points to an elimination of interneurons from the brain after loss of the afferent input. The TUNEL-labeled sections contained a number of fluorescent structures in soma clusters 9 and 10, many of which were approximately the same size as the neuronal somata. This could indicate that the decrease in the number of neurons may be the result of cell death. We examined 35 brains of ADI animals for the presence of dying cells after antennular amputation. Three to six individuals were killed and fixed each day after the amputation during a period of $18 \mathrm{~d}$, and their brains were sectioned and treated simultaneously with the TUNEL method.

TUNEL profiles in these preparations were confined to projection neurons and local interneurons. Counts of TUNEL profiles on the amputated and unamputated side of the brain produced totals that ranged from 0 to 57 on the amputated side and 0 to 20 on the unamputated side. Counts between individuals were highly variable, but in each individual the TUNEL profile count on the amputated side of the brain was higher than on the unamputated side (Figs. 10, 11 $A$ ). In a second experiment, animals of the same age were subjected to amputation and then killed at regular intervals thereafter. Plotting the ratio of the TUNEL profiles on the amputated to unamputated sides shows that there are always more profiles on the amputated side than on the unamputated side (Fig. 11B).

In addition, we examined five adults at 2-6 d after antennular amputation. The results are similar to the experiments in the ADI amputations, in that the TUNEL profile number on the amputated side was always higher than on the control side. In three unamputated adults, very nearly the same number of TUNEL profiles was found on both sides of the brain. 

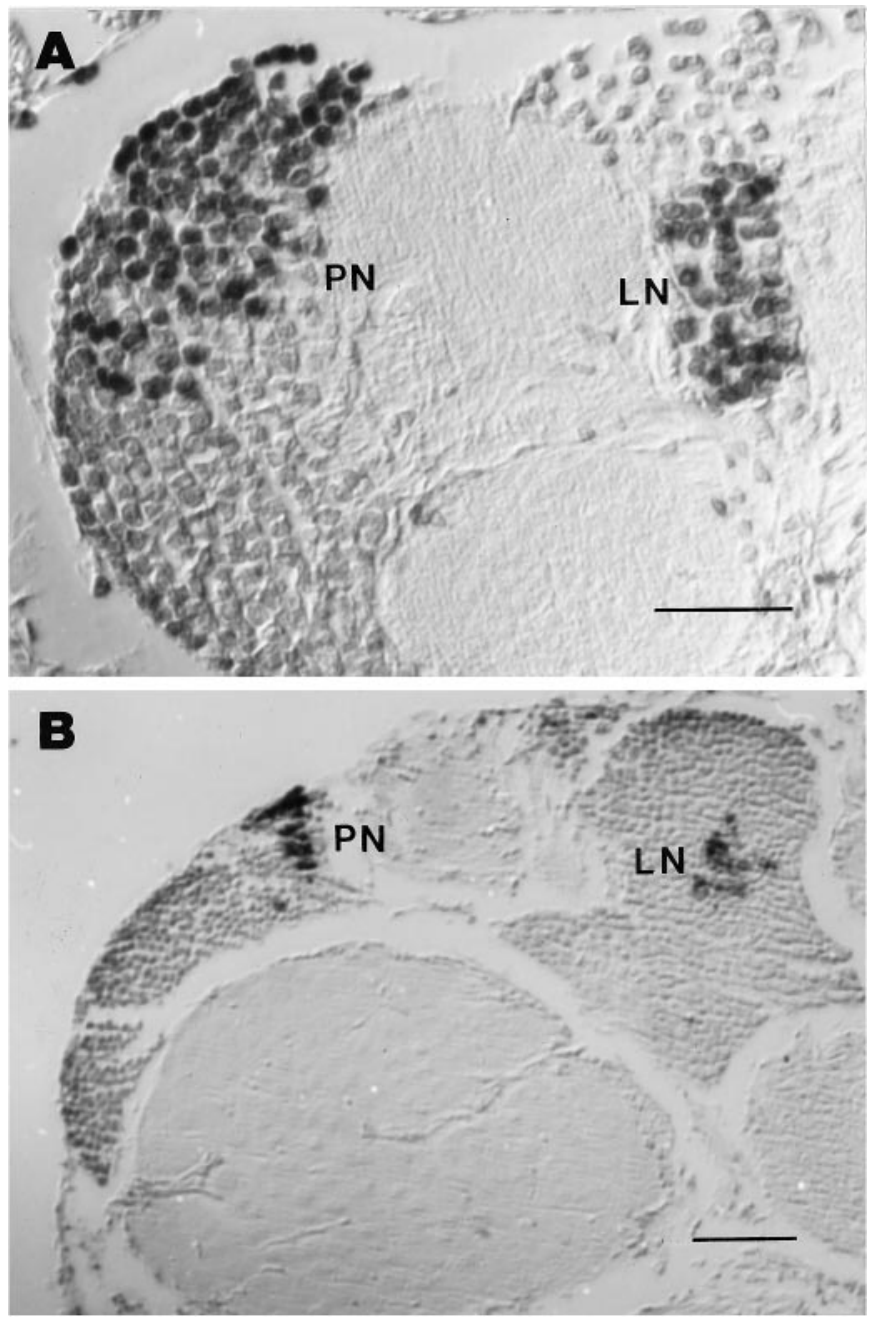

Figure 9. BrdU-labeled projection neurons $(P N)$ and local interneurons $(L N)$ in $10 \mu \mathrm{m}$ wax sections taken horizontally through the brain. Only the left side of the brain is shown in which the projection neuron cluster is on the left and the local interneuron cluster is on the right. A, ADI animal. $B$, Animal with a carapace length of $4.0 \mathrm{~cm}$. Scale bars: $A, 50 \mu \mathrm{m}$; $B, 100 \mu \mathrm{m}$.

\section{Recovery after amputation}

Complete reconstitution of an amputated antennule needs several molts, making such observations on large adults difficult because each intermolt period is between 6 and 12 months. The process can be observed over shorter time spans in small animals, which are accessible for amputation from the POI stage (Fig. 12). Amputations on POI individuals were performed while they were still attached to the mother, and the animals were killed at different molt stages after the operation, ranging from animals that had molted twice to reach ADI (carapace length, $0.4 \mathrm{~cm}$ ) to one animal that had molted approximately 12 times (carapace length, $1.5 \mathrm{~cm}$ ). Counts of aesthetascs and measurements of olfactory lobe and projection neuron volumes were obtained for all animals.

The olfactory lobe on the amputated side had a volume that was $\sim 60 \%$ of the control side in ADI animals, two molts after amputation. Small reconstituted antennules were visible in these ADI individuals. Although no aesthetascs were present on the outside of the antennule, clusters of one to five olfactory receptor cell somata could be seen beneath the cuticle in fresh prepara-

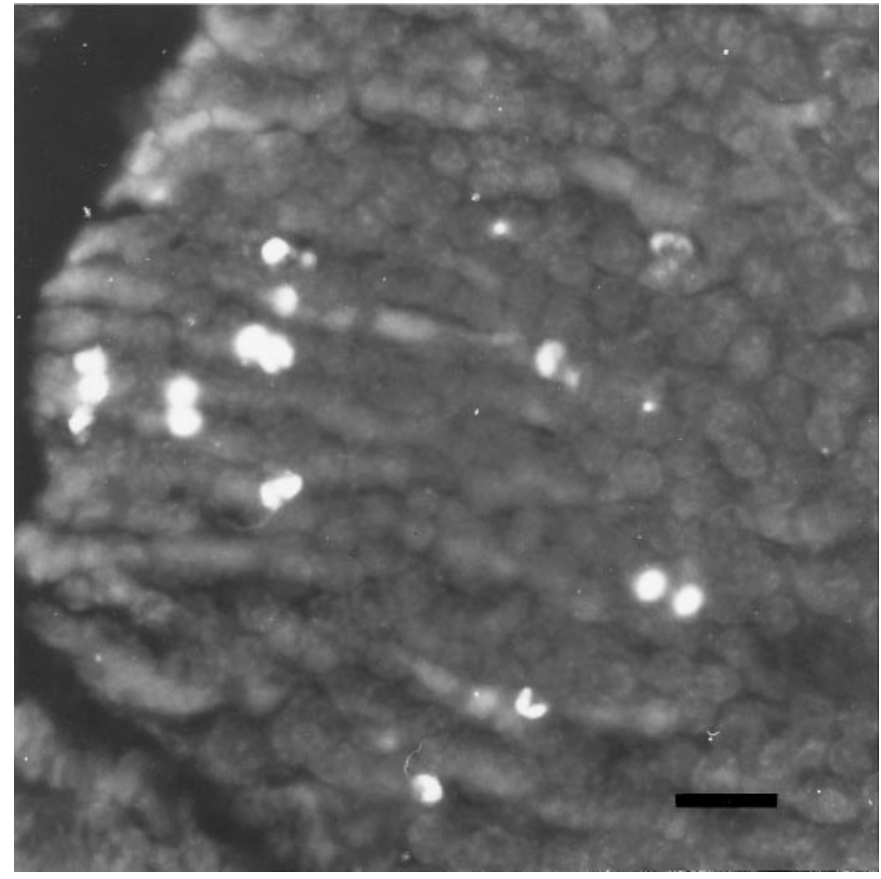

Figure 10. TUNEL profiles among the cell somata of the projection neurons, revealed by the TUNEL method and fluorescence microscopy. Only intensely fluorescing profiles were counted. Scale bar, $20 \mu \mathrm{m}$.

tions with differential interference contrast microscopy. Three molts after amputation of the antennule the olfactory lobe on the amputated side was $\sim 40 \%$ of the control side in one ADII animal. Eight aesthetascs were present on the partly reconstituted antennule, compared with approximately 12 on the control side. The first signs of recovery of the olfactory lobe volume appeared one molt later at ADIII, in which the olfactory volume of four animals lay between 45 and $65 \%$ of their controls: $11-15$ externalized aesthetascs, carried on well reconstituted antennules, appeared at the ADIII stage. At this stage, the control side contains approximately 15 aesthetascs. During the following two molts the antennules were completely reconstituted and matched the antennule on the unamputated side in terms of the number of segments and aesthetascs. Olfactory lobe volume on the amputated side regains the size of the control side by the fifth molt after amputation (Fig. 13).

Accumulated information on 21 adult animals, ranging in size from a carapace length of $3.5-4.5 \mathrm{~cm}$, and killed one, two, and three molts after amputation of the antennules, confirmed the results obtained from the juveniles. In all of these animals, removal of the antennule on one side resulted in a relatively rapid decline in the volume of the olfactory lobe on that side and in a slower decline in the projection neuron volume. After the third molt, 22 months after the amputation, the projection neuron volume was the same on the amputated as on the control sides, whereas recovery of the olfactory lobe and reconstitution of the antennule had reached only $70 \%$ of the control side.

\section{DISCUSSION}

The interneurons in the deutocerebral commissure of the Cherax that carry nonolfactory information to the accessory lobe abide by the invertebrate "rule" of numerical constancy. Set at approximately 400 large and approximately 1000 small axons at a very early age, these totals are maintained throughout the life of the 
A

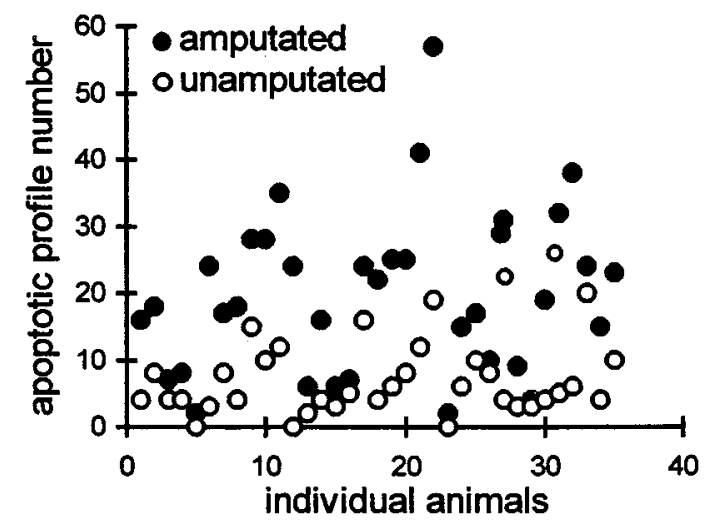

B

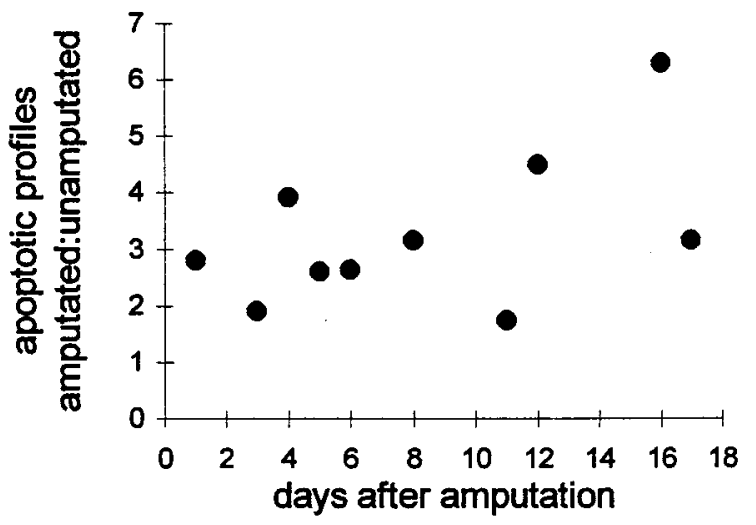

Figure 11. A, Counts of TUNEL profiles in 35 animals in which the number of profiles on the amputated side $(\bullet)$ is plotted with those on the unamputated side $(\bigcirc)$ in the same animal. The size of the animals ranged from POII to ADI, and the time between amputation and killing of animals ranged from 1 to $17 \mathrm{~d}$. The data are pooled here and show that in each individual more TUNEL profiles were counted on the amputated side than on the control side. $B$, The ratio of the profiles on the amputated side to the unamputated side for a series of animals that were all subjected to amputation at the ADI stage and then killed at intervals thereafter is shown on the abscissa.

animal. Enlargement of the accessory lobe during growth must be partly through the increase in the terminal arborizations of the interneurons of the deutocerebral commissure. The almost total (perhaps complete) immunity of the accessory lobe to amputation of the antennule in terms of volume loss is most likely attributable in part to the absence of any terminals from the olfactory receptor neurons.

The projection and local neurons provide a strong contrast to the interneurons in the deutocerebral commissure in that their numbers increase with the size of the animal and the number of olfactory receptor cells. The olfactory lobe, in contrast to the accessory lobe, is much more sensitive to antennular amputation because all of the olfactory receptor neurons end in the olfactory lobe.

Cell proliferation in the olfactory systems is known in many animals (Schmidt, 1997), but the comparison of proliferation rates in crustaceans with that of other animals is difficult because the temporal age of crustaceans is not related to body size. A well nourished crayfish in noncrowded, warm conditions, for example, can grow to a significantly greater size than a poorly nourished animal living for the same time in less optimal conditions. The

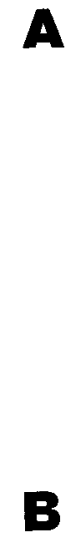

$\mathbf{B}$
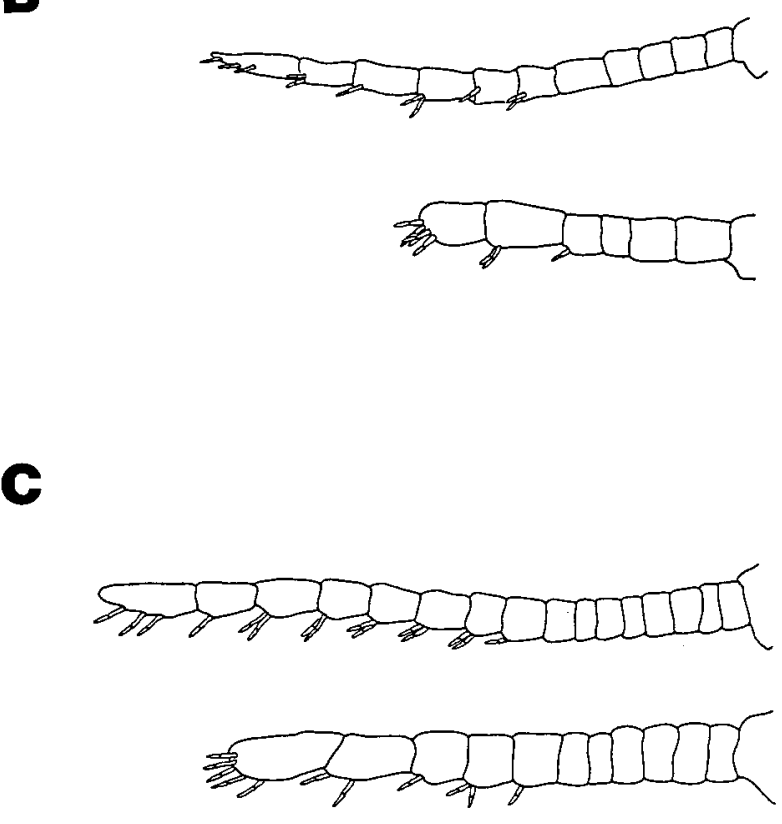

Figure 12. Stages in the reconstitution of an antennule of an animal in which one antennule was amputated at the POI stage. The drawings show the reconstituted and control antennules in the ADI $(A)$, ADII $(B)$, and ADIII $(C)$ stages. Scale bar, $0.5 \mathrm{~mm}$.

brain size, however, is yoked to body size, not age, and proliferation rates are therefore geared to environmental conditions and are different for each animal.

Despite the above, we can estimate the rate of net gain of projection neurons of different sized animals that were housed under similar conditions in the laboratory, knowing their pre- and post-molt sizes, the duration of the intermolt period, and, from the growth data, the numbers of projection neurons they should have had at the start of the observation period. From these data we calculated that an animal progressing from AD1 to a carapace length of $1.6 \mathrm{~cm}$ in 5.5 months (when its projection neurons were counted) gained approximately 400 projection neurons per day. An ADI animal that was pulse-labeled with BrdU for $4 \mathrm{~d}$ was calculated to have added 301 cells per day. An animal that grew from a carapace length of 4.2 to $4.6 \mathrm{~cm}$ in 1 year was calculated to have added approximately 54 cells per day. An animal with a carapace length of $4.4 \mathrm{~cm}$ that was BrdU pulse-labeled yielded a cell count of 45 cells per day. There is, therefore, a clear decrease in the proliferation rate with an increase in animal size, a situa- 


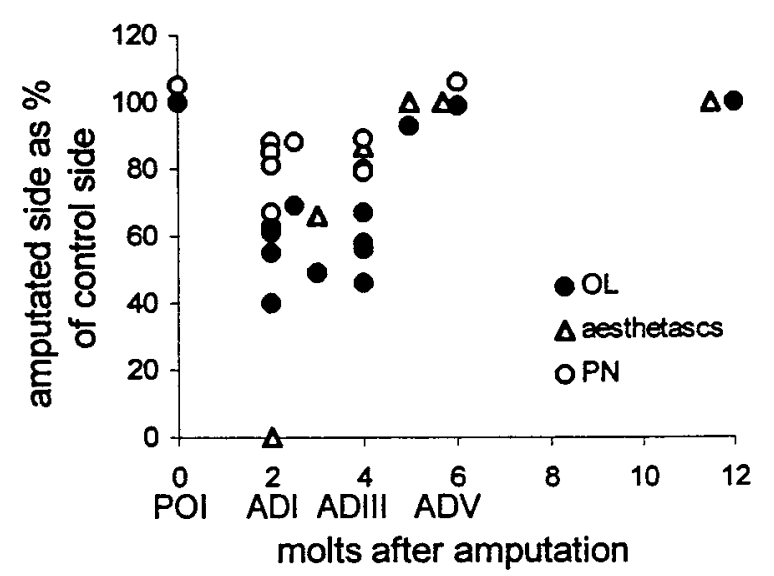

Figure 13. Recovery of the olfactory lobe after amputation of the antennule at POI. Olfactory lobe volume is reduced by $40 \%$ after the first molt and continues to decrease between the POII and ADI. Recovery begins during ADI and is complete by ADV.

tion very similar to that of the granule cells in the adult rat olfactory bulb (Kaplan et al., 1985). The situation is nevertheless further complicated in crayfish by their ability to adjust their growth rate to the conditions under which they live. It is quite possible that crayfish of the same size living under different conditions will have significantly different projection neuron proliferation rates.

The presence of cell death among the projection and local neurons, indicated by the decrease in both cell cluster volume and TUNEL profiles, adds a new and interesting dimension to the growth of the crayfish olfactory system, because it raises the possibility that a certain population of projection and local neurons are responsive to changes in their afferent input. It is clear that the loss of cells must occur at a lower rate than cell proliferation, because there is net gain in projection and local neurons that keeps pace with the growth of the animal. We find TUNEL profiles in animals of all sizes, suggesting an ongoing process that perhaps is related to cell proliferation.

Cell death in developing nervous systems has often been observed and various explanations have been provided, including the removal of an overproduction of neurons. This may explain the loss of neurons in smaller crayfish, but in the larger animals the loss of the projection and local neurons in Cherax could be coupled with olfactory receptor cell "turnover." In this process, olfactory receptor cells are shed from the distal end of the antennule, and new cells are added to the proximal end of the receptor array (Sandeman and Sandeman, 1996). Although this can be measured only when the animal molts by comparing the exuviae with the new antennule, the process of afferent cell death and proliferation is more than likely taking place during the entire intermolt period. This means that the projection and local neurons are being subjected to the continual departure of old, and the arrival of new, afferent axons.

There are two interesting possibilities here. The first is that the targeted projection or local neurons tolerate the loss of the degenerating afferents and accept newly developed afferent terminals in the vacated spaces. The second possibility is that the projection and local neurons associated with the degenerating afferents also degenerate. Some evidence to support the second possibility comes from our results in which amputations were performed both at a very early stage (POI and ADI) and on larger adults animals. Here we see a decrease in the volume of the olfactory lobe caused by the loss of afferent terminals, and a decline in the number of projection neurons induced by the absence of the afferent input. In both, there is an increase in the numbers of TUNEL profiles on the amputated side.

The interaction between the afferents and the projection neurons in the small animals is not only one of downregulation. Reconstitution of the antennule is attended by the recovery of the normal volume of the olfactory lobe caused by the ingrowing afferents, and the projection neuron cell number is also restored. This could be achieved either by an upregulation of the cell proliferation by the incoming afferents or by a downregulation of cell death, allowing the amputated side to "catch up" to the unamputated side, which it does in a relatively short period (Fig. 11). Our results showing a $30 \%$ increase in the BrdU-labeled cells on the reconstituting side of a brain after amputation support the notion that repair includes the upregulation of cell proliferation. The rapid growth of the reconstituting antennule and cell proliferation slow down once the antennule has reached the same size as the control, unamputated side. From then on the growth rate is symmetrical, and the ratio of olfactory receptor neurons to the total number of projection and local neurons is maintained at approximately 1:5 in all sizes of animals.

In conclusion, it would appear that artificially upsetting the afferent-to-central interneuron ratio by amputation of the antennule results in downregulation and then upregulation of the olfactory interneuron numbers and leads us to propose that in the crayfish, normal death and replacement of the olfactory receptor neurons during turnover is accompanied by a similar process in which the olfactory interneurons adjust their numbers in relation to the input.

\section{REFERENCES}

Altman JS (1980) Toluidine blue as a rapid stain for nerve cell bodies in intact ganglia. In: Neuroanatomical techniques: insect nervous system (Strausfeld NJ, Miller TA, eds), pp 21-23. New York: Springer.

Atwood HL, Wojtowicz JM (1986) Short-term and long-term plasticity and physiological differentiation of crustacean motor synapses. Int Rev Neurobiol 28:275-362.

Bieber M, Fuldner D (1979) Brain growth during the adult stage of a holometabolous insect. Naturwissenschaften 66:426.

Blest AD, Davie PS (1980) Reduced silver impregnations derived from the Holmes technique. In: Neuroanatomical techniques: insect nervous system (Strausfeld NJ, Miller TA, eds), pp 98-117. New York: Springer.

Brunjes P (1994) Unilateral naris closure and olfactory system development. Brain Res Rev 19:146-160.

Cayre M, Strambi C, Strambi A (1994) Neurogenesis in an adult insect brain and its hormonal control. Nature 368:57-59.

Cayre M, Strambi C, Charpin P, Augier R, Meyer MR, Edwards JS, Strambi A (1996) Neurogenesis in adult insect mushroom bodies. J Comp Neurol 371:300-310.

Cohen LB, Wachowiak M, Fang J (1996) Optical imaging of olfactoryevoked activity in the brain of the spiny lobster. Soc Neurosci Abstr 22:1075.

Gascuel J, Masson C (1990) Developmental study of afferented and deafferented bee antennal lobes. J Neurobiol 22:795-810.

Gavrieli Y, Sherman Y, Ben-Sasson SA (1992) Identification of programmed cell death in situ via specific labelling of nuclear DNA fragmentation. J Cell Biol 119:493-501.

Gronenberg W, Heeren S, Hölldobler B (1996) Age-dependent and taskrelated morphological changes in the brain and the mushroom bodies of the ant Camponotus floridanus. J Exp Biol 199:2011-2019.

Harzsch S, Dawirs RR (1996) Neurogenesis in the developing crab brain: postembryonic generation of neurons persists beyond metamorphosis. J Neurobiol 29:384-398.

Harzsch S, Schmidt M (1996) Brain development in adult crayfish includes the generation of new deutocerebral neurons. Proc Ger Zool Soc 89:1-50.

Harzsch S, Miller J, Benton J, Beltz B (1997) Neurogenesis in the developing lobster CNS. Soc Neurosci Abstr 23:318. 
Heisenberg M, Heusipp M, Wanke C (1995) Structural plasticity in the Drosophila brain. J Neurosci 15:1951-1960.

Helluy SM, Ruchhoeft ML, Beltz BS (1995) Development of the olfactory and accessory lobes in the American lobster: an allometric analysis and its implications for the deutocerebral structure of decapods. J Comp Neurol 357:433-445.

Hildebrand JG, Rössler W, Tolbert LP (1997) Postembryonic development in the olfactory system in the moth Manduca sexta: primaryafferent control of glomerular development. Semin Cell Dev Biol 8:163-170.

Kaplan MS, McNelly NA, Hinds JW (1985) Population dynamics of adult-formed granule neurons of the rat olfactory bulb. J Comp Neurol 239:117-125.

Letourneau JG (1976) Addition of sensory structures and associated neurons to the crayfish telson during development. J Comp Physiol 110:13-23.

Mellon DeF, Alones V (1993) Cellular organization and growth related plasticity of the crayfish olfactory midbrain. Microsc Res Tech 24:231-259.

Mellon DeF, Tuten HR, Redick J (1989) Distribution of radioactive leucine following uptake of olfactory sensory neurons in normal and heteromorphic antennules. J Comp Neurol 280:645-662.

Monti-Graziadei AG, Graziadei PPC (1979) Neurogenesis and neuron reconstitution in the olfactory system of mammals. II. Degeneration and reconstitution of the olfactory sensory neurons after axotomy. J Neurocytol 8:197-213.

Monti-Graziadei AG, Graziadei PPC (1992) Sensory reinnervation after partial removal of the olfactory bulb. J Comp Neurol 316:32-44.

Najbauer J, Leon M (1995) Olfactory experience modulates apoptosis in the developing olfactory bulb. Brain Res 674:245-251.

Negoescu A, Lorimier P, Labat-Moleur F, Drouet C, Robert C, Guillermet C, Brambilla C, Brambilla E (1996) In situ apoptotic cell labeling by the TUNEL method: improvement and evaluation of cell preparations. J Histochem Cytochem 44:959-968.

Nonclercq D, Reverse D, Toubeau G, Laurent G, Zanen J, HeusonStennon JA (1997) In situ demonstration of apoptotic germ cells in an experimental model of chemical castration. Biochemica 1:12-15.

Rosselli-Austin L, Williams J (1990) Enriched neonatal odor exposure leads to increased numbers of olfactory bulb mitral and granule cells. Dev Brain Res 51:135-137.

Sandeman DC, Sandeman RE, Derby C, Schmidt M (1992) Morphology of the brain of crayfish, crabs, and spiny lobsters: a common nomenclature for homologous structures. Biol Bull 183:304-326.

Sandeman DC, Scholtz G, Sandeman RE (1993) Brain evolution in decapod Crustacea. J Exp Zool 265:112-133.
Sandeman D, Beltz B, Sandeman R (1995) Crayfish brain interneurons that converge with serotonin giant cells in accessory lobe glomeruli. J Comp Neurol 352:263-279.

Sandeman R, Sandeman D (1990) Development and identified neural systems in the crayfish brain. In: Frontiers in crustacean neurobiology (Wiese K, Krenz WD, Tautz J, Reichert H, Mulloney B, eds), pp 498-508. Basel: Birkhauser Verlag.

Sandeman R, Sandeman D (1991) Stages in the development of the embryo of the freshwater crayfish Cherax destructor. Roux's Arch Dev Biol 200:27-37.

Sandeman RE, Sandeman DC (1996) Pre- and post-embryonic development, growth and turnover of olfactory receptor neurones in crayfish antennules. J Exp Biol 199:2409-2418.

Sandeman RE, Watson AHD, Sandeman DC (1995) Ultrastructure of the synaptic terminals of the dorsal giant serotonin-IR neuron and deutocerebral commissure interneurons in the accessory and olfactory lobes of the crayfish. J Comp Neurol 361:617-632.

Schmidt M (1997) Continuous neurogenesis in the olfactory brain of adult shore crabs, Carcinus maenas. Brain Res 767:131-143.

Schneiderman AM, Hildebrand JG (1985) Sexually dimorphic development of the insect olfactory pathway. Trends Neurosci 8:494-499.

Schneiderman AM, Matsumoto SG, Hildebrand JG (1982) Transsexually grafted antennae influence development of sexually dimorphic neurones in moth brain. Nature 298:844-846.

Schneiderman AM, Hildebrand JG, Brennan MM, Tumlinson JH (1986) Trans-sexually grafted antennae alter pheromone-directed behaviour in a moth. Nature 323:801-803.

Schwob JE, Mieleszko Szumowski KE, Stasky AA (1992) Olfactory sensory neurons are trophically dependent on the olfactory bulb for their prolonged survival. J Neurosci 12:3896-3919.

Stewart BA, Atwood HL (1992) Synaptic plasticity in a regenerated crayfish phasic motoneuron. J Neurobiol 23:881-889.

Technau GM (1984) Fiber number in the mushroom bodies of adult Drosophila melanogaster depends on age, sex and experience. J Neurogenet 1:113-126.

Thomaidou D, Mione MC, Cavanagh JFR, Parnavelas JG (1997) Apoptosis and its relation to the cell death cycle in the developing cerebral cortex. J Neurosci 17:1075-1085.

Wachowiak M, Diebel CE, Ache BW (1996) Functional organization of olfactory processing in the accessory lobe of the spiny lobster. J Comp Physiol [A] 178:211-226.

Winnington PA, Napper RM, Mercer AR (1996) Structural plasticity of identified glomeruli in the antennal lobes of the adult worker honey bee. J Comp Neurol 365:479-490. 